J. Lake Sci.(湖泊科学), 2008, 20(3): 380-388

http://www.jlakes.org. E-mail: jlakes@niglas.ac.cn

(C)2008 by Journal of Lake Sciences

\title{
太湖秋季真光层深度空间分布及浮游植物初级生产力的估算*
}

\author{
张运林 ${ }^{1}$, 冯 胜 ${ }^{1}$, 马荣华 ${ }^{1}$, 刘明亮 ${ }^{2}$, 秦伯强 ${ }^{1}$ \\ (1: 中国科学院南京地理与湖泊研究所湖泊与环境国家重点实验室, 南京 210008) \\ (2: 南京农业大学, 南京 210095)
}

摘 要: 基于 2004 年 10 月对全湖 67 个采样点水下光合有效辐射(photosynthetically active radiation: PAR)和各光学活性物质浓 度的测定，分析了真光层深度的空间分布及其影响因素. 利用实测的叶绿素 a 浓度, 真光层深度, PAR 强度，由水温计算得到 的最佳固碳速率以及由经纬度计算的日照周期等，在垂向归纳模型(vertically generalized production model: VGPM)的支持下估 算了全湖秋季浮游植物初级生产力. 真光层深度的变化范围为 $0.37-5.27 \mathrm{~m}$ (均值为 $1.52 \pm 1.06 \mathrm{~m}$ ), 高值出现在东太湖、胥口湾、 东西山之间等水生植物分布茂盛的草型湖区，而在梅梁湾、湖心区以及西南面的开阔湖区真光层深度均较小. 回归分析显示, 真光层深度主要受制于非色素颗粒物浓度, 浮游植物和溶解性有机物的贡献相对要小得多. 叶绿素 a 浓度和 VGPM 模型估算 的浮游植物初级生产力变化范围分别 1.21-53.59 $\mathrm{\mu g} / \mathrm{L} 、 77.4-2484.9 \mathrm{mg} /\left(\mathrm{m}^{2} \cdot \mathrm{d}\right)$, 其时空分布基本一致, 高值出现在富营养化的 藻型湖区梅梁湾, 低值出现在胥口湾和西南开阔湖区. VGPM 模型和经验模式对比结果显示两者值比较接近并存在显著相关 $\left(r^{2}=0.79, p<0.0001\right)$, 两类模型全湖的均值分别为 $694.5 \pm 492.0 、 719.8 \pm 315.4 \mathrm{mg} /\left(\mathrm{m}^{2} \cdot \mathrm{d}\right)$, 但由于 VGPM 模型考虑到真光层深度、 温度、PAR 强度以及日照周期对初级生产力的影响, 其变化范围明显大于经验模型, 也更能反映初级生产力的空间变化. 关键词: 太湖; 真光层深度; VGPM模型; 叶绿素a；浮游植物初级生产力

\section{Spatial pattern of euphotic depth and estimation of phytoplankton primary production in Lake Taihu in autumn 2004}

ZHANG Yunlin ${ }^{1}$, FENG Shen ${ }^{1}$, MA Ronghua ${ }^{1}$, LIU Mingliang ${ }^{2}$ \& QIN Boqiang ${ }^{1}$

(1: State Key Laboratory of Lake Science and Environment, Nanjing Institute of Geography and Limnology, Chinese Academy of Sciences, Nanjing 210008, P.R.China)

(2: Nanjing Agriculture University, Nanjing 210095, P.R.China)

Abstract: Based on the underwater photosynthetically active radiation (PAR) profile measurement and the concentrations of the optically active substances, the spatial patter and affecting factors of euphotic depth in Lake Taihu are discussed. Phytoplankton primary production $\left(P P_{\mathrm{eu}}\right)$ of all the lakes in autumn 2004 is estimated using the vertically generalized production model (VGPM) based on measured surface chlorophyll-a (Chl.a) concentration, euphotic depth, water temperature, PAR at the water surface, photoperiod and water depth. Euphotic depth ranges from 0.37 to $5.27 \mathrm{~m}$ with a mean value of $1.52 \pm 1.06 \mathrm{~m}$. The higher euphotic depth appears in the macrophyte-dominated lake regions such as East Lake Taihu, Xukou Bay and water area between Xishan and Dongshan Islands. In contrast, the lower euphotic depth is found in algal-dominated lake region such as Meiliang Bay and the southwestern open water. The regression analyses show that euphotic depth is mainly controlled by nonpigment particle matter, next to phytoplankton and chromophoric dissolved organic matter (CDOM). Nonpigment particle matter can explain 96.7\% variation of euphotic depth. The ranges of Chl.a concentration and estimated $P P_{\text {eu }}$ are $1.21-53.59 \mu \mathrm{g} / \mathrm{L}, 77.4-2484.9 \mathrm{mg} /\left(\mathrm{m}^{2} \cdot \mathrm{d}\right), \mathrm{respectively}$. The estimated daily mean $P P_{\text {eu }}$ distribution coincides closely with that of Chl.a concentration. Higher Chl.a and $P P_{\mathrm{eu}}$ values are recorded in Meiliang Bay and lower values are found in Xukou Bay or southwestern open water. There is a good correlation between VGPM $P P_{\mathrm{eu}}$

* 中国科学院知识创新工程方向性项目(KZCX2-YW-419)、国家自然科学基金项目(40730529, 40671138)和江苏省自然科学 基金项目(BK2006580)联合资助. 2007-05-28 收稿; 2007-09-17 收修改稿. 张运林, 男, 1976 年生，博士，副研究员; E-mail: ylzhang@niglas.ac.cn. 
and primary production from the empirical model $\left(\mathrm{PP}_{\mathrm{em}}\right)\left(r^{2}=0.79, p<0.0001\right)$. Daily mean $\mathrm{PP}_{\mathrm{eu}}$ and $\mathrm{PP}_{\mathrm{em}}$ of all the lakes are 694.5 $\pm 492.0,719.8 \pm 315.4 \mathrm{mg} /\left(\mathrm{m}^{2} \cdot \mathrm{d}\right)$, respectively. Although the ranges of the two methods differ, the mean values are very close. $\mathrm{PP}_{\mathrm{e}}$ more accurately captures spatial variation by considering the effect of euphotic depth, water temperature, surface PAR and photoperiod on PP.

Keywords: Lake Taihu; euphotic depth; VGPM model; chlorophyll-a; phytoplankton primary production

真光层深度 (euphotic depth)定义为水柱中支持净初级生产力的部分, 其底部为临界深度, 即水柱日 净初级生产力为零值的深度. 在海洋、湖泊、河流等水域生态系统中浮游植物基本上都分布在这一层, 在 研究浮游植物初级生产力时一般以真光层深度为下界, 因而该深度有时也被称为光合层厚度. 真光层深 度一方面取决于水体中各类物质对光的衰减, 另一方面还与到达水表面的光强有关. 但为了研究的方便 和规范化, 大多数研究采用 $1 \%$ 表面光强深度来代替真光层深度, 当然也有人将水下光强为 $14 \mu \mathrm{mol} /\left(\mathrm{m}^{2} \cdot \mathrm{s}\right)$ 对应的深度称之为真光层深度 ${ }^{[1]}$. 不同的水体真光层深度差异显著, 在清洁的海洋其值可以高达 $100 \mathrm{~m}$ 以 上, 而在浑浊的内陆水体有时则只有几十厘米 ${ }^{[2]}$. 由于浮游植物光合作用主要发生在这一层, 因此其深 度直接影响到浮游植物水体初级生产力 ${ }^{[3-4]}$, 同样也往往决定沉水植物的分布.

关于太湖浮游植物初级生产力的观测研究进行的较多, 也定量探讨了各生态因子对初级生产力的影 响 ${ }^{[5-9]}$, 但这些研究大多集中在梅梁湾, 缺乏对其它湖区的研究. 由于初级生产力现场测定一般采样黑白 瓶溶氧法或碳同位素标记法，测定费时费力，加之现场测定无论是从空间分布还是时间序列的角度看, 都是 “离散” 的. 在海洋里, 近几十年来的研究成果相继提出了利用与初级生产力相关的生态因子以及 叶绿素 $\mathrm{a}$ 浓度计算初级生产力的许多经验的、半经验半理论的或理论的算法, 并对各种方法的原理、可 行性、可靠性做了分析和讨论 ${ }^{[10-16]}$. Behrenfeld \& Falkowski ${ }^{[17]}$ 标准化叶绿素浓度、光照周期和真光层深 度后, 发现所有实测的初级生产力垂直分布呈相同形式, 在表层由于光抑制作用光合速率降低, 在次表 层光强最适合处出现最大值，之后随光强减弱而降低. 表层光强越强，最适光合速率出现的位置越深， 在此基础上建立了初级生产力深度垂向归纳模型(VGPM 模型: Vertically Generalized Production Model).

近10年来许多学者分别根据VGPM模型或改进的VGPM模型，通过水色遥感反演的资料估算了各海 区的初级生产力并研究其时空变化 ${ }^{[18-22]}$. 国内的王海黎等 ${ }^{[23]}$ 、李国胜等 ${ }^{[24]}$ 也基于SeaWiFS卫星水色遥感 资料估算了东海的初级生产力并取得较好的效果. 尽管VGPM模型最初设计是基于遥感资料作为输人来 计算真光层内初级生产力, 但也先后有人利用实测的叶绿素a浓度、真光层深度及其它资料作为模型输人 来计算初级生产力 ${ }^{[25-26]}$, 但所有这些工作均集中在海洋里. 对于太湖这种水体光学特性复杂多变的二类 水体，由于缺乏高精度的水质遥感反演模型，因而如果利用遥感资料作为模型输人，可能会带来计算结 果的巨大误差. 本文尝试利用VGPM模型以及实测的全湖真光层深度、叶绿素a浓度、光合有效辐射 (photosynthetically active radiation: PAR)强度, 由水温计算得到的最佳固碳速率以及由经纬度计算的日照 周期等，估算了2004年全湖秋季初级生产力，并与经验模型进行对比，进而分析其空间分布和演化机理， 弥补初级生产力现场观测在空间分布上的不足.

\section{1 材料与方法}

2004 年 10 月 20-29 日在太湖均匀布设了 67 个采样点(图 1). 野外原位记录采样点经纬度, 测定水 下 PAR 强度、水温、水深, 并采集水样回实验室分析总悬浮物、叶绿素 $\mathrm{a} 、$ 脱镁叶绿素浓度和有色可溶 性有机物(chromophoric dissolved organic matter: CDOM)吸收系数.

\section{1 采样与测量方法}

悬浮物用 $\mathrm{GF} / \mathrm{C}$ 滤纸过滤，采用电子天平称重法测定. 叶绿素 $\mathrm{a}$ 的测定采用分光光度法，用 $90 \%$ 的热 酒精萃取提取色素, 然后在分光光度计上测定吸光度换算得到叶绿素 $\mathrm{a}$ 和脱镁叶绿素浓度 ${ }^{[27]}$. Hoogenboom \& Dekker曾在荷兰浅水湖泊采用如下计算式分离总悬浮物中的色素和非色素颗粒物 ${ }^{[28]}$ :

$$
C_{\text {Tripton }}=C_{\mathrm{TSM}^{-}} 0.07 C_{\text {Chl.a+Pa }}
$$

式中, $C_{\text {Tripton、 }} C_{\mathrm{TSM}} 、 C_{\mathrm{Chl.a+Pa} a}$ 分别表示非色素、总悬浮物和浮游植物色素(叶绿素a和脱镁叶绿素之和)浓 
度. 考虑到太湖与荷兰许多浅水湖泊的类似性, 这里假定式(1)也适合太湖, 由此可以得到非色素颗粒物 浓度. CDOM吸收系数的测定参见文献[29].

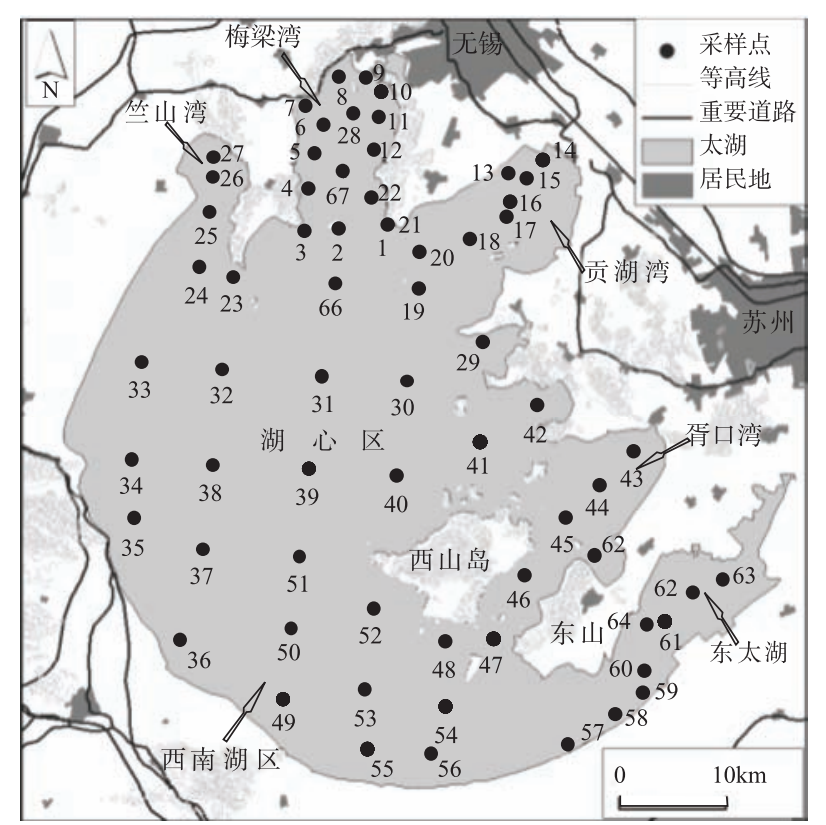

图 1 采样站点分布图

Fig.1 Distribution of sampling stations

\section{2 真光层的定义及计算}

在 VGPM 模型中, 真光层深度是一个主要的输人参数 ${ }^{[17-18,20]}$. 在海洋一类水体中可以根据其与叶绿素 $\mathrm{a}$ 浓度的经验关系加以确定, 对于太湖这种以非藻类颗粒物吸收为主的二类水体, 真光层深度很大程度上受 制于悬浮物浓度 ${ }^{[30]}$, 本研究是根据 PAR 的原位剖面测量计算得到. 将辐照度为水表面辐照度 $1 \%$ 处的深 度视为真光层深度, 其与漫射衰减系数存在如下定量关系:

$$
Z_{\text {eu }}(\mathrm{PAR})=4.605 / K_{\mathrm{d}}(\mathrm{PAR})
$$

式中, $Z_{\mathrm{eu}}(\mathrm{PAR})$ 为PAR真光层深度, $K_{\mathrm{d}}(\mathrm{PAR})$ 为漫射衰减系数.

漫射衰减系数按下式计算 ${ }^{[2]}$ :

$$
K_{\mathrm{d}}(\mathrm{PAR})=-\frac{1}{z} \ln \frac{E_{\mathrm{d}}(\mathrm{PAR}, z)}{E_{\mathrm{d}}(\mathrm{PAR}, 0)}
$$

式中, $K_{\mathrm{d}}(\mathrm{PAR})$ 为 PAR 漫射衰减系数, $z$ 为从湖面到测量处的深度, $E_{\mathrm{d}}(\mathrm{PAR}, z)$ 为深度 $z$ 处的向下辐照度, $E_{\mathrm{d}}(\mathrm{PAR}, 0)$ 为水面起始向下辐照度, 其测定选用美国 LI-COR 公司的 Li-cor 192SA 水下光量子仪, 分水下 $0,0.2,0.5,0.75,1.0,1.5 \mathrm{~m}$ 共 6 层, 每层记录 3 个数据, 取平均值. $K_{\mathrm{d}}(\mathrm{PAR})$ 值通过对不同深度处水下辐照度 进行指数回归得到, 回归效果只有当 $r^{2} \geqslant 0.95$, 深度数 $n \geqslant 3$ 时其 $K_{\mathrm{d}}(\mathrm{PAR})$ 值才被接受. 实际拟合的效果 $r^{2}$ 的均值为 0.9964 .

\section{3 浮游植物初级生产力估算方法}

Behrenfeld \& Falkowski ${ }^{[17]}$ 收集了从 1971 年到 1994 年期间, 从北纬 80 度到南纬 70 度范围共 1698 个站点包含了 I 类水体和 II 类水体的不同来源的实测资料. 根据这些实测资料发现在初级生产力中标准 化叶绿素 a 浓度、光照周期和真光层深度后, 所有实测资料的初级生产力垂直分布呈相同形式. 在此基础 上, Behrenfeld \& Falkowski ${ }^{[17]}$ 建立了海洋初级生产力计算的 VGPM 模型. VGPM 模型经历了长时期、大 范围、不同水域的上千个站点的上万个实测数据的验证, 不仅计算精确, 而且应用广泛, 它的表达式为: 


$$
P P_{\text {eu }}=P_{\text {opt }}^{\mathrm{B}} \cdot D_{\text {irr }} \cdot \int_{z=0}^{Z_{\text {cut }}} \frac{\left(1-\mathrm{e}^{\frac{-E_{z}}{E_{\max }}}\right) \mathrm{e}^{\left(\beta_{\mathrm{d}} \cdot E_{z}\right)}}{\left(1-\mathrm{e}^{\frac{-E_{\text {opt }}}{E_{\max }}}\right) \mathrm{e}^{\left(\beta_{\mathrm{d}} \cdot E_{\mathrm{opt}}\right)}} \cdot C_{z} \mathrm{~d} z
$$

式中: $P P_{\mathrm{eu}}$ 为从表层到真光层积分的初级生产力 $\left(\mathrm{mg} / \mathrm{m}^{2}\right), P_{\mathrm{opt}} \mathrm{B}$ 为水柱的最大碳固定速率 $(\mathrm{mgC} /(\mathrm{mgChl} \cdot \mathrm{h})), C_{z}$ 为 $z$ 深度的叶绿素浓度, $E_{z}$ 为 $z$ 深度的 PAR 强度 (mol quanta $\left./ \mathrm{m}^{2}\right), E_{\mathrm{opt}}$ 为 $P_{\mathrm{opt}}$ 所在深 度的 PAR 强度, $\beta_{\mathrm{d}}$ 为 P-I 曲线 (光合作用速率与光强之间的对应关系)的初始斜率, $D_{\mathrm{irr}}$ 为光照周期, $Z_{\mathrm{eu}}$ 为 真光层深度.

Behrenfeld \& Falkowski ${ }^{[17]}$ 对模型计算的结果和实测结果进行比较后认为, 模型反映了 $79 \%$ 初级生产 力的时空变化 $(n=10857)$. 对模型进一步简化, 可以得到水柱积分初级生产力计算的核心公式:

$$
P P_{\text {eu }}=0.66125 P_{\text {opt }}^{\mathrm{B}} \cdot \frac{E_{0}}{E_{0}+4.1} \cdot Z_{\text {eu }} \cdot C_{\text {opt }} \cdot D_{\text {ir }}
$$

式中: $C_{\mathrm{opt}}$ 为 $P_{\mathrm{opt}} \mathrm{B}$ 所在处的叶绿素 $\mathrm{a}$ 浓度, 可以用表层叶绿素 $\mathrm{a}$ 浓度代替; $E_{0}$ 为湖表面 PAR 强度; $Z_{\mathrm{eu}}$ 为 真光层深度(当水深小于真光层深度就用水深代替). $D_{\text {irr }}$ 可以根据水柱所在的位置(经纬度)和时间(在一年 中的天数)来计算.

由于叶绿素进行光合作用主要是受酶的控制, 而酶的活性又主要受温度控制, 因此一般认为 $P_{\mathrm{opt}}{ }^{\mathrm{B}}$ 是 表层温度的函数, 但存在多个换算关系式, 本研究使用 Behrenfeld \& Falkowski 提出的下列关系式 ${ }^{[17]}$ :

$$
P_{\text {opt }}^{\mathrm{B}}= \begin{cases}1.13 & T<-1.0 \\ 4.00 & T>28.5 \\ P_{\text {opt }}^{\mathrm{B}^{\prime}} & \text { 其它 }\end{cases}
$$

其中: $P_{\mathrm{opt}}^{\mathrm{B}^{\prime}}=1.2956+2.749 \times 10^{-1} T+6.17 \times 10^{-2} T^{2}-2.05 \times 10^{-2} T^{3}+2.462 \times 10^{-3} T^{4}-1.348 \times 10^{-4} T^{5}+3.4132 \times 10^{-6} T^{6}$ $-3.27 \times 10^{-8} T^{7}$. 式中, $T$ 为表层湖水温度 $\left({ }^{\circ} \mathrm{C}\right)$. 由于各站点采样的具体时间不一样, 而水温又存在日变化, 因而本研究以全湖实测水温的平均值代替各站点水温值.

太湖地区 PAR 强度数据自来太湖湖泊生态系统研究站的气象观测场, 用 10 月 20-29 日的平均值代替.

\section{2 结果与讨论}

\section{1 真光层深度的空间分布及影响因素}

2004 年 10 月 20-29 日实测 PAR 的衰减系数变化范围和均值分别为 $0.87-12.43 \mathrm{~m}^{-1}, 4.42 \pm 2.64 \mathrm{~m}^{-1}$, 对 应的真光层深度的变化范围和均值分别为 $0.37-5.27 \mathrm{~m}, 1.52 \pm 1.06 \mathrm{~m}$, 最大值出现在东太湖与大太湖交接 的 57 号点, 最小值出现在太湖西南部开阔湖区的 49 号点, 其位置比较临近太湖的主要河流西苦溪的人 湖河口小梅口(图 2). 真光层深度空间分布显示其高值出现在东太湖、胥口湾、东西山之间等水生植物分 布茂盛的草型湖区，而在梅梁湾、湖心区以及西南面的开阔湖区真光层深度均较小，与以前利用悬浮物 浓度计算得到的太湖典型湖区真光层深度空间变化一致 ${ }^{[30]}$. 与以前的研究相比, 本次研究全湖样本量明 显增加, 样点的分布也比较均匀, 能得到全湖详细的真光层深度分布图. 为探讨真光层深度的影响因素, 将真光层深度与非色素颗粒物、总色素以及 CDOM 在 $440 \mathrm{~nm}$ 处吸收系数进行回归分析(图 3), 尽管真光 层深度与非色素颗粒物、浮游植物色素以及 CDOM 吸收系数均存在显著性相关, 但与非色素颗粒物的相 关性最好, 并且明显要高于其它两者, 与总色素的相关性其次, 与 CDOM 吸收的相关性最差, 反映了太 湖这类大型浅水湖泊, 由于频繁的沉积物再悬浮, 非色素颗粒物浓度较高, 其对真光层的贡献最大, 其 次则是浮游植物色素, CDOM 的贡献相对要小得多.

由于真光层深度与漫射衰减系数为定量的反比关系, 通过对衰减系数的分析可以进一步了解各光学 活性物质浓度对真光层深度的影响和贡献份额. 为此对 PAR 衰减系数与非色素颗粒物、浮游植物色素以 及 CDOM 吸收系数进行逐步多元回归分析, 结果如下:

$$
K_{\mathrm{d}}(\mathrm{PAR})=0.068( \pm 0.001) C_{\text {Tripton }}+1.352( \pm 0.080)\left(r^{2}=0.975, p<0.0001\right)
$$



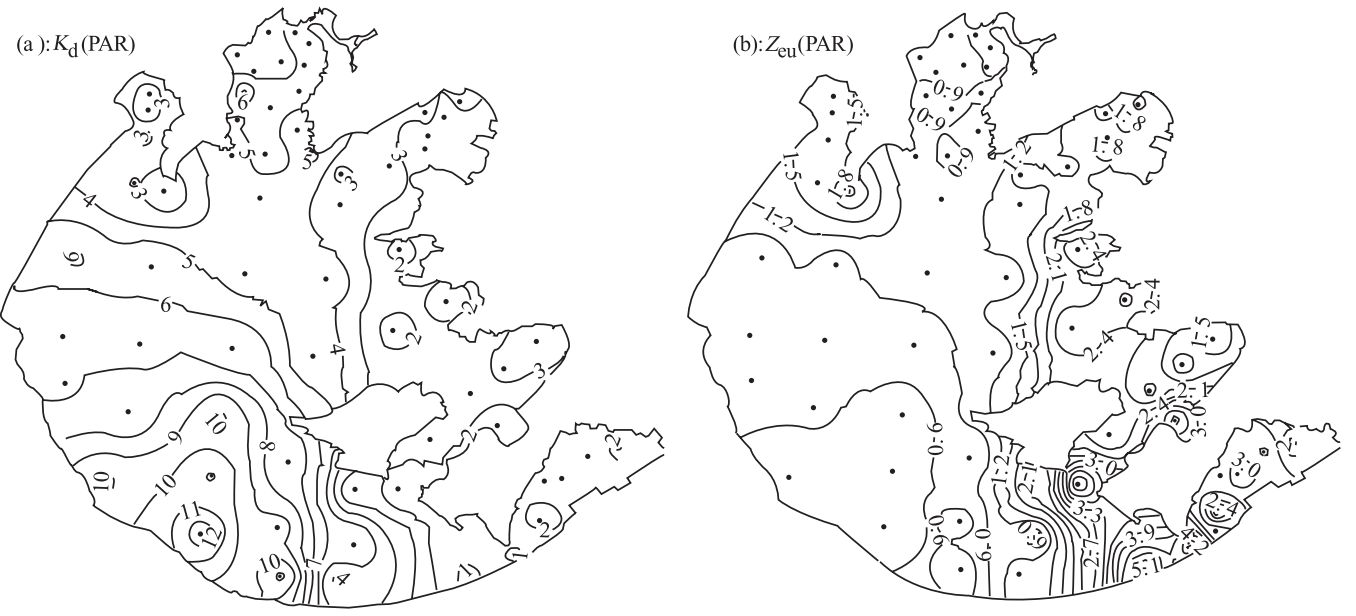

图 2 PAR 衰减系数及真光层深度的空间分布

Fig.2 Spatial patterns of PAR diffuse attenuation coefficient and euphotic depth in Lake Taihu
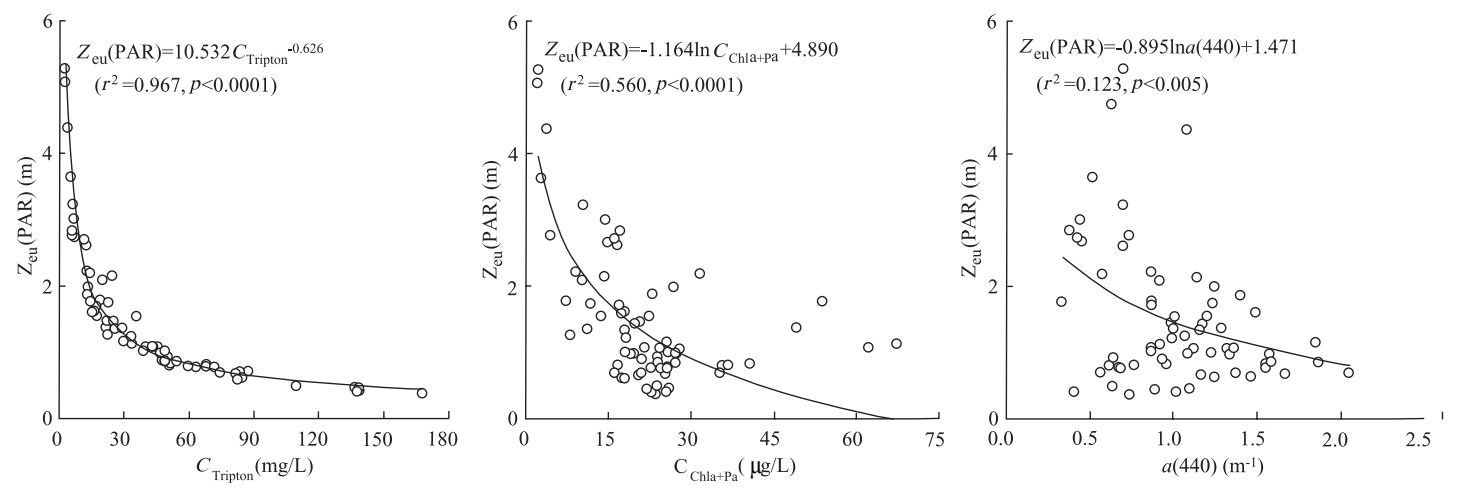

图 3 PAR 真光层深度与光学活性物质浓度的相关分析

Fig.3 Correlations between PAR euphotic depth and tripton, pigment concentration, CDOM absorption

$K_{\mathrm{d}}(\mathrm{PAR})=0.067( \pm 0.001) C_{\text {Tripton }}+0.014( \pm 0.004) C_{\mathrm{Chl} . \mathrm{a}+\mathrm{Pa}}+1.087( \pm 0.103)\left(r^{2}=0.979, p<0.0001\right)$

$K_{\mathrm{d}}(\mathrm{PAR})=0.067( \pm 0.001) C_{\text {Tripton }}+0.013( \pm 0.004) C_{\text {Chl.a+Pa }}+0.258( \pm 0.121) a(440)+0.862( \pm 0.146)\left(r^{2}=0.981, p<0.0001\right)(9)$

逐步多元回归分析结果显示, 非色素颗粒物能解释 $97.5 \%$ 的衰减系数变化, 当总色素和 CDOM 吸收 增加到回归方程后解释率分别为 $97.9 \%$ 、98.1\%, 由此可见非色素颗粒物在 PAR 漫射衰减系数以及真光 层深度变化上占绝对主导地位, 这与以前的研究结果一致 ${ }^{[30]}$. 在太湖沉积物再悬浮引起的高浓度非色素 颗粒物对真光层深度起到决定性的作用. Bachmann 等 ${ }^{[31]}$ 用湖泊的动力比 (为湖泊面积 $\left(\mathrm{km}^{2}\right)$ 的平方根除以 平均湖深 (m)), 对包括 Apopka 湖在内的 36 个佛罗里达浅水湖泊的面积、深度、风浪引起的水运动和沉 积物悬浮, 水质变化之间关系进行了分析. 当某湖的动力比大于 0.8 时, 整个湖的沉积物都有可能受制于 波浪骚动. 太湖的动力比高达 25.6, 因而全年大部分时段沉积物都要受到风力扰动而悬浮，再加之其处 于亚热带季风区并受台风的影响, 风速较大且全年盛行, 致使太湖底泥更容易发生再悬浮, 水体中悬浮 物浓度较高, 如此次观测全湖悬浮物浓度平均值为 $46.5 \mathrm{mg} / \mathrm{L}$. 风浪作用引起底泥的再悬浮增加了光的衰 减, 致使真光层深度降低.

2.2 叶绿素 $\mathrm{a}$ 和初级生产力的空间分布

图 4 给出了叶绿素 a 和 VGPM 模型计算得到初级生产力的空间分布. 叶绿素 $\mathrm{a}$ 的变化范围为 
$1.21-53.59 \mu \mathrm{g} / \mathrm{L}$, 均值为 $14.4 \pm 9.1 \mu \mathrm{g} / \mathrm{L}$; 初级生产力的变化范围和均值分别为 $77.4-2484.9 \mathrm{mg} /\left(\mathrm{m}^{2} \cdot \mathrm{d}\right) 、 694.5$ $\pm 492.0 \mathrm{mg} /\left(\mathrm{m}^{2} \cdot \mathrm{d}\right)$. 总体而言, 叶绿素 $\mathrm{a}$ 和初级生产力的空间分布较为一致, 高值出现在富营养化蓝藻水华频 繁爆发的梅梁湾, 其中最高值在梅梁湾湾口的 21 号点, 而在贡湖湾和东太湖湾内也有一个等值线密集区. 这 与以前的一些现场观测有些出人, 尤其在草型湖区的东太湖叶绿素 $\mathrm{a}$ 和初级生产力应该为低值, 而贡湖湾则 可能由于风浪作用将梅梁湾大量浮游植物带人湾内造成叶绿素 a 值偏高, 同时由于低的非色素颗粒物带来高 的真光层深度, 使得该区域初级生产力偏高. 在大太湖、西南面的开阔湖区以及胥口湾等湖区叶绿素 $\mathrm{a}$ 和初级 生产力的值较低, 最低值出现在 58 号点的东太湖湾口部分. 尽管日平均初级生产力与叶绿素 $\mathrm{a}$ 浓度的空间分 布基本上一致, 但初级生产力的最高值与最低值的比值明显要低于叶绿素 $\mathrm{a}$, 两者最高与最低值的比值分别为 44.3、32.1. 分析原因主要是受真光层深度的影响, 由于真光层深度与叶绿素 a 浓度是反相关关系, 高的叶 绿素 $\mathrm{a}$ 浓度带来低的真光层深度, 从而使得初级生产力的空间变化没有叶绿素 a 大. 对叶绿素 a 和 VGPM 模型估算的初级生产力进行线性回归发现, 叶绿素 a 浓度大概能解释 $79 \%$ 的初级生产力的变化 $\left(P P_{\mathrm{eu}}=\right.$ 47.74Chl.a $\left.+7.52, n=67, r^{2}=0.79\right)$, 说明叶绿素 a 浓度在初级生产力估算中的重要性, 其精度往往关系到 初级生产力的精确估算.
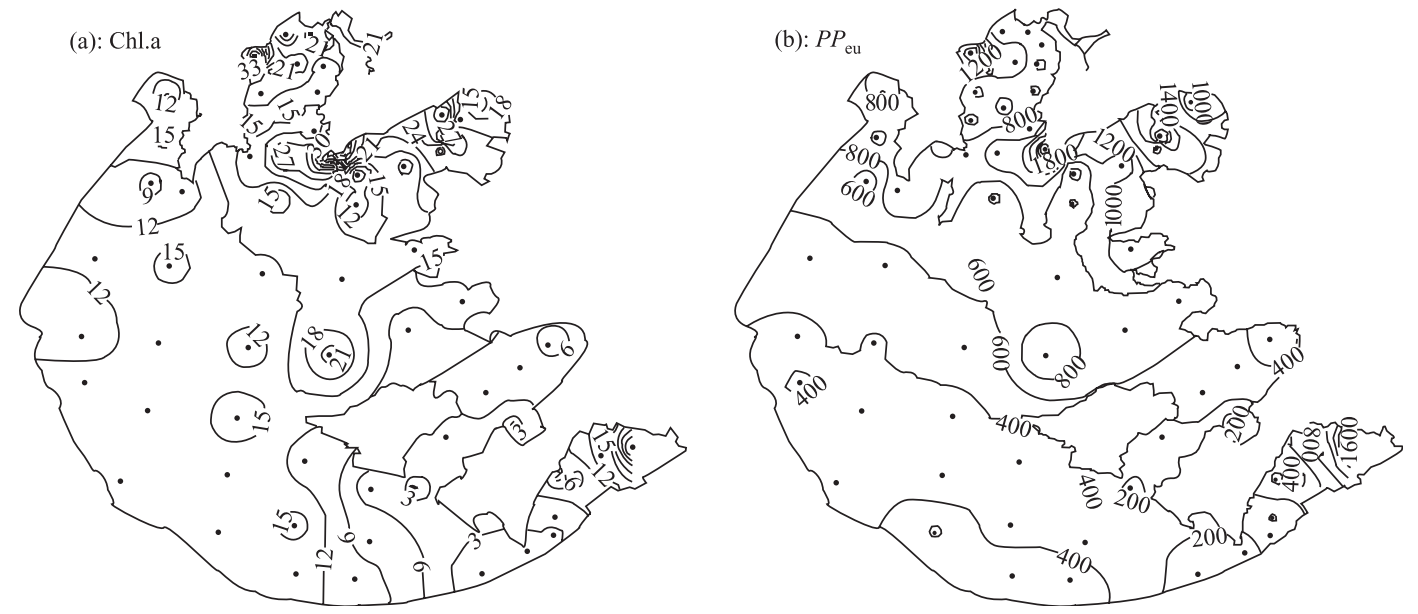

图 4 叶绿素 $\mathrm{a}$ 和初级生产力的空间分布

Fig.4 Spatial patterns of chlorophyll-a (Chl.a) concentration and primary production $\left(P P_{\mathrm{eu}}\right)$

太湖秋季日平均初级生产力明显高于同纬度同时期海洋里的值 ${ }^{[23-24]}$, 但低于城郊湖泊武汉东湖和杭 州西湖 ${ }^{[32]}$. 以前对太湖初级生产力的实测一般都集中梅梁湾 ${ }^{[5-9]}$, 对其他湖区了解很少, 本研究给出了初 级生产力的平面分布, 尽管还缺乏初级生产力的季节演替, 但在很大程度上弥补以前研究的不足, 有利 于进一步深人了解湖泊生态系统结构和营养盐的内循环.

将全湖 67 个站点的日平均初级生产力均值看成是太湖各点日平均初级生产力, 乘上太湖面积就可 以计算得到全湖日平均初级生产力, 2004 年秋季太湖日平均初级生产力为 $1.62 \times 10^{3} \mathrm{t} / \mathrm{d}$, 如果按 Redfield 比值 $\mathrm{C}: \mathrm{N}: \mathrm{P}=106: 16: 1$ 换算, 2004 年秋季太湖日平均初级生产的氮、磷分别为 $245.1 \mathrm{t}$ 和 15.3t. 需要说明的 是这里计算出来的氮、磷营养盐是静态的结果，并没有考虑营养盐在生态系统中的循环. 事实上，浮游植 物在利用营养盐进行光合作用合成有机物后会死亡降解，释放出营养盐，并参与到浮游植物下一次对营 养盐的利用中去.

\subsection{VGPM 模型值与经验模式值对比}

在海洋里 VGPM 模型估算初级生产力的精度很大程度上依赖表层叶绿素 $\mathrm{a}$ 浓度和真光层深度. 由于 太湖水光学特性的复杂性, 叶绿素 $\mathrm{a}$ 浓度的遥感反演精度有限, 用实测的叶绿素 $\mathrm{a}$ 浓度作为模型输人参数 可以在很大程度上降低估算值的误差. 为了检验 VGPM 模型的精度, 利用经验模型估算值与 VGPM 模型 估算值进行对比. 根据 1998-1999 年梅梁湾初级生产力的实测数据, 水柱积分的初级生产力和表层叶绿 


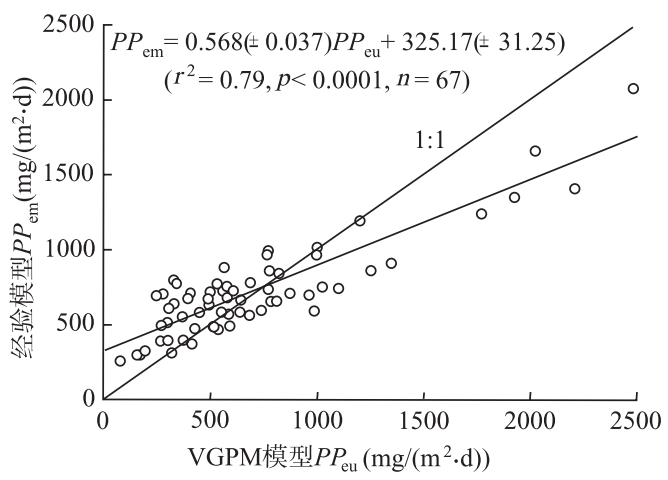

图 5 VGPM 模型和经验模式日初级生产力对比

Fig.5 Comparison between daily VGPM $P P_{\text {eu }}$ and empirical model $P P_{\mathrm{em}}$
素 a 浓度存在较好的相关性, 以两者之间的关系式建 立如下经验模式: $P P_{\mathrm{em}}=34.52 \mathrm{Chl} . \mathrm{a}+222.9, n=25, r^{2}=$ 0.76. 利用实测的表层叶绿素 a 浓度可直接得到全湖 各站点初级生产力的空间分布.

从 VGPM 模型和经验模式的结果来看(图 5), VGPM 模型计算的日平均生产力在 77.4-2484.9mg/ $\left(\mathrm{m}^{2} \cdot \mathrm{d}\right)$ 变化, 而经验模式的结果变动范围要小得多, 为 $264.5-2073.0 \mathrm{mg} /\left(\mathrm{m}^{2} \cdot \mathrm{d}\right)$. 在低的初级生产力情况 下, 经验模式值要高于 VGPM 模型值, 而在高的初 级生产力情况下，则是 VGPM 模型值高，在中间地 带两者差不多. 尽管 VGPM 模型值和经验模式值有 些偏离 $1: 1$ 关系线(尤其是在初级生产力非常低和非 常高情况), 但总体上 VGPM 模型和经验模式值还 是比较接近, 并且两者存在很好的相关性(图 5).

分析 VGPM 模型和经验模式的差异主要来自于温度、PAR 强度及日照周期、真光层深度的影响. 在 经验模式中未考虑这些因素对初级生产力的影响. 事实上初级生产力的影响因素有很多, 包括叶绿素 $\mathrm{a}$ 浓度、温度、到达湖面的 PAR 强度、光照周期和真光层深度，如实测初级生产力结果表明，在 $10-30^{\circ} \mathrm{C}$ 之间初级生产力与温度存在很好的指数函数关系 ${ }^{[8]}$. 梅梁湾 1995-2003 年 VGPM 模型估算的初级生产 力与水温、PAR 强度和日照周期相关分析显示它们之间均存在显著的正相关，并且与 VGPM 模型值相 关性均要高于与经验模式的相关性 ${ }^{[32]}$. 毫无疑问, 真光层深度会影响到水体浮游植物初级生产力, 但 对于太湖这类特定浅水湖泊而言，由于水浅在真光层深度较高的水域水深往往要低于真光层深度，其 初级生产力的计算就用水深代替真光层深度, 加之叶绿素 $\mathrm{a}$ 对初级生产力的解释率较高, 因此初级生产 力尽管与真光层深度存在正相关, 但由于受水深、叶绿素 $\mathrm{a}$ 等因素的影响这种相关性却并不显著 $(r=0.13$, $p=0.28)$.

从 2004 年秋季全湖 67 站点 VGPM 模型和经验模式值得到平均日初级生产力对比来看, 全湖平均值 非常接近, 分别为 $694.5 \pm 492.0 、 719.8 \pm 315.4 \mathrm{mg} /\left(\mathrm{m}^{2} \cdot \mathrm{d}\right)$, 说明利用 VGPM 模型来估算梅梁湾初级生产力 具有较高的准确性，加之其有坚实的理论基础，还可应用到其他水域估算初级生产力，有很好的普适性. 如能建立起适合太湖的二类水体生物光学水质遥感模型, 将遥感图像上提取的叶绿素 a 浓度和真光层深度 作为模型输人，借助遥感数据的高精度的时空分辨率，再利用 VGPM 模型就能得到更高精度的初级生产力 的时空分布规律，有利于太湖的湖泊富营养化治理. 但由于太湖是一个容易受风浪扰动的大型浅水湖泊, 属典型二类水体, 水体光学特性复杂多变, 要建立适合太湖水体的水质遥感模型, 需开展太湖水体吸收 系数、散射系数、衰减系数等生物光学特性的研究.

\section{3 结论}

(1) 全湖真光层深度的变化范围和均值分别为 $0.37-5.27 \mathrm{~m}, 1.52 \pm 1.06 \mathrm{~m}$, 高值出现在东太湖、胥口湾 等水生植物分布茂盛的草型湖区, 而在梅梁湾、湖心区以及西南面开阔湖区真光层深度均较小. 真光层 深度受非色素颗粒物影响最大, 其次为浮游植物色素和 CDOM 吸收, 反映了浅水湖泊沉积物再悬浮造成 的非色素颗粒物增加明显降低了真光层深度.

(2) 叶绿素 $\mathrm{a}$ 和初级生产力的空间分布较为一致，高值出现在富营养化蓝藻水华频繁爆发的梅梁湾，低 值出现在大太湖、西南面的开阔湖区以及胥口湾等草型湖区. 叶绿素 a 浓度大概能解释 79\%的初级生产力 的变化, 其精确遥感反演关系到初级生产力的精确估算. 2004 年秋季太湖日平均初级生产力为 $1.62 \times 10^{3} \mathrm{t} / \mathrm{d}$.

(3) VGPM 模型和经验模式对比结果显示两者值比较接近, 但由于 VGPM 模型考虑到真光层深度、 温度、PAR 强度以及日照周期对初级生产力的影响, 其更能反映初级生产力的空间变化. 全湖初级生产 
力的估算大大弥补了先前太湖初级生产力现场测定空间分布上的不足, 有利于进一步深人了解湖泊生态 系统结构和营养盐的内循环.

致谢: 感谢中国科学院太湖湖泊生态系统研究站提供光合有效辐射数据. 野外采样得到唐军武、李铜基、 孙小洲、宋庆君、高飞、杨安安、李刚、朱建华等同志的鼎力帮助，南京师范大学的乐成峰同志帮助绘 制文中等值线分布图, 在此一并表示谢意.

\section{4 参考文献}

[1] Reinart A, Arst H, Erm A et al. Optical and biological properties of Lake Ülemiste, water reservoir of the city of Tallinn II: Light climate in Lake Ülemiste. Lakes \& Reservoirs: Research and Management, 2001, 6: 75-84.

[2] Kirk JTO. Light and photosynthesis in aquatic ecosystem. Cambridge, Britain: Cambridge University Press, 1994: 47-144.

[3] Hinojosa FD, Castro GG, Zavala JAS et al. The effect of vertical mixing on primary production in a bay of the Gulf of California. Estuar Coast Shelf S, 1997, 45: 135-148.

[4] Oliver RL, Whittington J, Lorenz Z et al. The influence of vertical mixing on the photoinhibition of variable chlorophyll a fluorescence and its inclusion in a model of phytoplankton photosynthesis. J Plankton Res, 2003, 25(9): 1107-1129.

[5] 蔡后建, 陈宇炜, 蔡启铭等.太湖梅梁湾口浮游植物初级生产力及其相关因素关系的研究. 湖泊科学, 1994, 6(4): 340-347.

[6] 陈宇炜, 高锡云, Dokulil M. 太湖梅梁湾浮游植物动态及其初级生产力周年变化的研究. 见: 蔡启铭主编. 太湖环境生态 研究(一). 北京: 气象出版社, 1998: 98-108.

[7] 杨顶田, 陈伟民, 陈宇炜等. 太湖梅梁湾水体中初级生产力的光学检验. 湖泊科学, 2002, 14(4): 363-368.

[8] 张运林, 秦伯强, 陈伟民等. 太湖梅梁湾浮游植物叶绿素 a 和初级生产力. 应用生态学报, 2004, 15(11): $2127-2131$.

[9] 张运林, 秦伯强, 陈伟民等. 太湖梅梁湾春季浮游植物初级生产力. 湖泊科学, 2005, 17(1): 81-86.

[10] Ryther JHR, Yentsch CS. The estimation of phytoplankton production in the ocean from cholorophyll and light data. Limnolo \& Oceanogr, 1957, 2: 281-286.

[11] Smith RC, Eppley RW, Baker KS. Correlation of primary production as measured aboard ship in southern California coastal 1 water and as estimated from satellite chlorophyll images. Mar Biol, 1982, 66: 281-288.

[12] Eppley RW, Stewart E, Abbott MR. Estimating ocean primary production from satellite chlorophyll, introduction to regional differences and statistics for the southern California bight. J Plankton Res, 1985, 7(1): 57-70.

[13] Platt T. Primary production of the ocean water column as a function of surface light intensity: algorithms for remote sensing. Deep-Sea Research, 1986, 33: 149-163.

[14] Morel A, Berthon JF. Surface pigments, algal biomass profiles and potential production of the euphotic layer: relationships reinvestigated in view of remote-sensing applications. Limnolo \& Oceanogr, 1989, 34: 1545-1562.

[15] Platt T, Sathyendranath S. Estimators of primary production for interpretation of remotely sensed data on ocean color. $J$ Geophysical Res, 1993, 98: 14561-14576.

[16] Michael JB, Paul GF. A consumer's guide to phytoplankton primary productivity models. Limnolo \& Oceanogr, 1997, 42(7): 1479-1491.

[17] Behrenfeld MJ, Falkowski PG. Photosynthetic rates derived from satellite-based chlorophyll concentration. Limnolo \& Oceanogr, 1997, 42: 1-20.

[18] Moore JK, Abbott R. Phytoplankton chlorophyll distributions and primary production in the Southern Ocean. J Geophysical Res, 2000, 105: 28709-28722.

[19] Yoo S, Kim HC. Suppression and enhancement of the spring bloom in the southwestern East Sea/Japan Sea. Deep-Sea Research II, 2004, 51: 1093-1111.

[20] Mizobata K, Saitoh S. Variability of Bering Sea eddies and primary productivity along the shelf edge during 1998-2000 using satellite multisensor remote sensing. J Mar System, 2004, 50: 101-111.

[21] Goes JI, Sasaoka K, Gomes HR et al. A comparison of the seasonality and interannual variability of phytoplankton biomass and 
production in the Western and Eastern Gyres of the subarctic Pacific using multi-sensor satellite data. J Oceanogr, 2004, 60: $75-91$.

[22] Muller-Kargera F, Varela R, Thunell R et al. Processes of coastal upwelling and carbon flux in the Cariaco Basin. Deep-Sea Research II, 2004, 51: 927-943.

[23] 王海黎, 赵朝方, 李丽萍等. 用卫星资料估算东海的初级生产力. 见: 胡敦欣等著. 东海海洋通量关键过程研究. 北京: 海洋出版社, 2000: 149-158.

[24] 李国胜, 王 芳. 东海初级生产力遥感反演及其时空演化机制. 地理学报, 2003, 58(4): 483-493.

[25] Bode A, Varela M. Mesoscale estimations of primary production in shelf waters: a case study in the Golfo Artabro (NW Spain). J Exp Mar Biol Ecol, 1998, 229: 111-131.

[26] Holm-Hansena O, Naganobub M, Kawaguchib S et al. Factors influencing the distribution, biomass, and productivity of phytoplankton in the Scotia Sea and adjoining waters. Deep-Sea Research II, 2004, 51: 1333-1350.

[27] 陈宇炜, 高锡云. 浮游植物叶绿素a含量测定方法的比较测定. 湖泊科学, 2000, 12(2): 185-188.

[28] Hoogenboom J, Dekker AG. Simulation of the medium-resolution imaging spectrometer MERIS performance for detecting chlorophyll-a over turbid inland waters. SPIE Proc, 1997, 2963: 440-447.

[29] 张运林, 秦伯强, 朱广伟等. 长江中下游浅水湖泊沉积物再悬浮物对水下光场的影响研究一一龙感湖和太湖为例. 中 国科学(D 辑), 2005, 35(增刊 II ): 101-110.

[30] 张运林, 秦伯强, 胡维平等. 太湖典型湖区真光层深度的时空变化及其生态意义. 中国科学(D 辑), 地球科学, 2006, 36(3): 287-296.

[31] Bachmann RW, Hoyer MV, Canfield DE. The potential for wave disturbance in shallow Florida lakes. Lake Reserv Manage, 2000, 16: 281-291.

[32] Zhang YL, Qin BQ, Liu ML. Temporal-spatial variations of chlorophyll a and primary production in Meiliang Bay, Lake Taihu, China from 1995 to 2003. J Plankton Res, 2007, 29(8): 707-719. 